\title{
Pengaruh Model Pembelajaran Remap STAD Terhadap Pemberdayaan Keterampilan Literasi Sains Peserta Didik
}

\author{
Ferry Irawan $^{1}$, Siti Zubaidah ${ }^{1}$, Sulisetijono ${ }^{1}$ \\ ${ }^{1}$ Pendidikan Biologi-Universitas Negeri Malang
}

\begin{tabular}{l} 
INFO ARTIKEL \\
\hline Riwayat Artikel: \\
Diterima: $01-04-2020$ \\
Disetujui: $12-08-2020$ \\
\hline
\end{tabular}

\section{Kata kunci:}

science literation skills; Remap STAD learning model; keterampilan literasi Sains; model pembelajaran Remap STAD

\author{
Alamat Korespondensi: \\ Ferry Irawan \\ Pendidikan Biologi \\ Universitas Negeri Malang \\ Jalan Semarang 5 Malang \\ E-mail: Irawanferry778@gmail.com
}

\begin{abstract}
ABSTRAK
Abstract: Science literacy skills are basic skills that must be possessed by students as a provision to be able to integrate their basic understanding related to the coherent scientific concepts. This study aims to look at the effectiveness of the Remap STAD learning model to empower science literacy skills. The study was classified as quasy experimental research using Non equivalent pretest-posttest control group design. The population of 234 students includes students of class XI Science with a total of seven classes. The sample used was selected through the equivalence test. The instrument uses an essay test by disregarding indicators of scientific literacy skills. Data were analyzed using One Way Anacova Test. The results obtained that the Remap STAD learning model contributes to empower students' scientific literacy skills.
\end{abstract}

\begin{abstract}
Abstrak: Keterampilan literasi sains merupakan keterampilan dasar yang harus dimiliki peserta didik agar mampu mengintegrasikan pemahaman dengan konsep ilmiah. Penelitian ini bertujuan untuk melihat pengaruh model pembelajaran Remap STAD terhadap pemberdayaan keterampilan literasi sains. Penelitian ini tergolong penelitian quasy experiment menggunakan Non equivalent pretest-posttest control group design. Populasi berjumlah 234 siswa mencakup siswa kelas XI IPA dengan total tujuh kelas. Sampel yang digunakan dipilih melalui hasil uji kesetaraan. Instrumen menggunakan tes esai mengacuh pada indikator keterampilan literasi sains. Analisis menggunakan One Way Anacova Test dan hasilnya model pembelajaran Remap STAD berpengaruh terhadap keterampilan literasi sains peserta didik.
\end{abstract}

Perkembangan abad 21 menuntut setiap peserta didik dapat menggunakan metode ilmiah dalam menelusuri fenomenafenomena ilmiah (Miller, 2018). Salah satu keterampilan yang harus dikuasai oleh peserta didik dalam memahami kompleksitas fenomena sains dan mengintegrasikannya dengan konsep ilmiah adalah keterampilan literasi sains. Keterampilan literasi sains sangat berkaitan erat dengan penguasaan konsep-konsep ilmiah yang melibatkan peserta didik untuk mengaplikasikan pengetahuan dan proses sains dalam kehidupan sehar-hari (Sample, 2020), dan melatih peserta didik dapat membuat keputusan berdasarkan logika dan memahami proses yang mendasari ilmu yang mereka dapatkan dalam kegiatan pembelajaran atau melalui fenomena-fenomena alam yang mereka temui dalam kehidupan nyata (Güneş \& Bahçivan, 2018).

Literasi sains terbagi menjadi tiga dimensi utama, yaitu (a) dimensi konten (content dimention) yang mengkaji kemampuan peserta didik untuk melihat ketersesuaian atau relevansi materi esensial yang diperoleh dalam kegiatan pembelajaran dan proses untuk mendapatkan ilmu tersebut, (b) dimensi kompetensi (competency dimention) yang sangat erat hubungannya dengan keterampilan dasar yang mencakup (1) kemampuan yang dimiliki peserta didik untuk dapat menggambarkan, menjelaskan secara rinci sehinga dapat memprediksi fenomena ilmiah, (2) keterampilan untuk dapat melakukan penyelidikan ilmiah yang secara langsung melibatkan keterampilan proses dasar sains, (c) dimensi fungsional (functional dimention) sebagai kemampuan untuk menafsirkan bukti ilmiah dan memberikan kesimpulan berdasarkan bukti ilmiah yang telah diperoleh (Kaya, Bahceci, \& Altuk, 2012). Literasi sains mempunyai perspektif yang lebih luas (Ahmad, Widén, \& Huvila, 2019), dan menjabarkan pemahaman terkait dengan materi pelajaran secara prosedural dan kegiatan penyelidikan ilmiah yang dilakukan secara empiris dan sistematis dengan menggunakan prosedur yang terbukti kebenaran dan kevalidannya (Burress, Mann, \& Neville, 2019).

Kemampuan literasi sains mempunyai keterkaitan terhadap proses pencapaian kognitif peserta didik dalam sains yang dapat membuat peserta didik mempunyai role model untuk memecahkan masalah, proses pengambilan keputusan, sikap dan nilai-nilai (Correia, Dazzani, \& Infante-Malachias, 2010) sehingga melalui pendekatan tersebut kita dapat melihat secara langsung setiap kegiatan yang dilakukan oleh peserta didik dalam memperoleh konsep secara ilmiah. Pengalaman sehari-hari 
yang diperoleh peserta didik agar mampu memprediksi fenomena alam, membaca artikel yang bernuansa sains (Hagermoser Sanetti \& Collier-Meek, 2019) melibatkan setiap peserta didik secara aktif untuk menghasilkan sebuah kesimpulan yang diungkapkan atau diinformasikan secara ilmiah, serta proses pengkajian ulang untuk melakukan penilaian terhadap kualitas informasi ilmiah yang didapatkan berdasarkan sumber dan metode yang digunakan termasuk bukti dari ide yang dikemukakan secara tepat (Costa \& Caldeira, 2018).

Penelitian yang dilakukan oleh Yaumi (2017) menunjukkan bahwa keterampilan literasi sains peserta didik masih mengalami permasalahan yang disebabkan karena siswa masih bersifat kaku dalam menyusun konsep terkait isu-isu yang dibahas dalam materi pembelajaran. Fakta lain yang diperoleh berdasarkan hasil penelitian Green \& Lambert (2018) menunjukkan bahwa kesadaran peserta didik terhadap konsep dasar sains belum cukup mumpuni, yang menyebabkan peserta didik hanya tergantung pada konsep yang disajikan oleh buku ajar di sekolah. Hal ini dapat menimbulkan adanya sifat ambigu terhadap keselarasan materi dengan konsep yang sebenarnya. Peserta didik tidak boleh diajarkan hanya sebatas pada toeritik saja karena mereka juga harus mempunyai kesadaran pentingnya sikap ilmiah dalam membangun sebuah gagasan (Nwagbo, 2006). Keterampilan dasar dapat menghantarkan peserta didik pada sikap telaten dalam mengelola setiap perspektif dan tetap mengahargai gagasan lain yang dapat mereka jadikan perbandingan informasi untuk menyusun konsep (Green, 2019).

Akses peningkatan keterampilan literasi sains peserta didik menurut PISA dapat dilakukan dengan melibatkan pihak sekolah dan masyarakat (PISA, 2015). Peserta didik harus mempunyai frekuensi membaca yang lebih tinngi yang dapat menunjang khasanah ilmu sains mereka dan dapat mengaplikasikan penggunaan konsep dalam setiap kegiatan pembelajaran (Suwono, 2015). Penyampaian informasi yang menarik akan meningkatkan stimulus peserta didik untuk terlibat aktif dalam menyikapi dan menanggapi fenomena yang mereka hadapi terkait dengan ilmu atau proses sains (Guo \& Huang, 2019). Fakta di Indonesia mengungkapkan bahwa keterampilan literasi sains peserta didik masih berada dalam level rendah, yang disebabkan oleh peserta didik masih jarang membaca dan mengakses informasi tentang konsep sains seacara umum yang diderivasikan dalam materi pembelajaran, dan peserta didik masih belum terbiasa mengerjakan soal-soal yang bernuansa literasi sains, serta model pembelajaran yang digunakan kurang efisien dalam memfasilitasi peserta didik melakukan proses investigasi ilmiah (Diana, Rachmatullah, \& Rahmawati, 2015) sehingga peserta didik harus dilatih menyusun pendapat ilmiah yang valid dan kajian literatur secara efektif dengan menerapkan model pembelajaran yang sesuai (Suwono, 2015).

Inovasi pembelajaran sangat diharapkan dapat diiplemenatsikan disetiap jenjang pendidikan sebagai bentuk aplikatif untuk melatihkan keterampilan literasi sains. Penelitian yang dilakukan oleh (Reiska, Soika, \& Soobard, 2015) menunjukkan bahwa kegiatan membaca merupakan alat utama bagi peserta didik untuk mengasosiasikan pemahaman mereka terkait konsep faktual yang melibatkan tingkat pemahaman terhadap setiap topik yang mereka baca atau pelajari. Kegiatan membaca harus dipadukan dengan pemetaan konsep secara spesisfik yang bertujuan untuk melatih peserta didik mengelompokkan atau melakukan proses pengkalsifikasian secara mendasar sehingga mereka tidak mengalami miskonsepsi terkait gagasan yang mereka telah dapatkan dan dilakukan secara kolaboratif sehingga informasi yang diperoleh dari berbagai sudut pandang atau perspektif yang mempunyai variasi (Zubaidah \& Corebima, 2016).

Model pembelajaran Remap Coople adalah model pembelajaran yang memadukan kegiatan membaca dan membuat peta konsep yang proses pelaksanaannya melalui model pembelajaran kooperatif (Zubaidah, 2016). Model pembelajaran ini sangat efektif untuk memfasilitasi peserta didik mengumpulkan informasi awal melalui kegitan membaca dan proses pembuatan peta konsep mengakomodasi peserta didik untuk mengategorikan ide mereka berdasarkan pendekatan tertentu. Kegiatan pembelajaran dengan menggunakan model STAD bertujuan menilai kinerja peserta didik secara berkelompok. Kesesuaian sintkas Remap dan STAD mempunyai hubungan yang integral untuk mengakomodasi kegiatan pembelajaran secara kolektif dalam memadukan ide-ide peserta didik (Zubaidah, 2016). Berdasarkan uraian yang telah disampaikan maka peneliti melakukan penelitian terkait pengaruh model pembelajaran Remap STAD terhadap pemberdayaan keterampilan literasi sains peserta didik. Hipotesis yang diajukan adalah terdapat pengaruh model pembelajaran Remap STAD terhadap keterampilan literasi sains peserta didik.

\section{METODE}

Penelitian ini termasuk jenis penelitian quasi experiment yang menggunakan desain Pre-test Post-test Non-equivalent Control Group Design. Penelitian berlangsung mulai September-November 2019. Populasi dalam penelitian ini adalah seluruh peserta didik kelas XI IPA di SMAN 4 Malang dengan total kelas berjumlah tujuh kelas. Sampel dipilih berdasarkan hasi uji kesetaraan sehingga diperoleh tiga kelas, yaitu kelas XI IPA-4 sebagai kelas eksperimen yang kegiatan pembelajran menerapkan model pembelajaran Remap STAD, XI IPA-1 sebagai kelas kontrol posotif dengan menggunakan model pembelajaran STAD serta kelas XI IPA 1 sebagai kontrol negatif yang dibelajarkan dengan menggunakan model pembelajaran konvensional (diskusi kelompok) yang sering digunakan oleh guru mata pelajaran Biologi.

Proses pengambilan dan pengumpulan data dengan menggunakan soal essay yang berjumlah enam soal yang disusun berdasarkan indikator keterampilan literasi sains menurut Gormally (2012) dengan kriteria soal esai yang dikembangkan berorientasi untuk melatihkan proses pemahaman konsep dan metode ilmiah serta umtuk mengkaji dan proses klasifikasi lanjut terhadap fakta atau konsep yang bersifat ilmiah. Kegiatan pembelajaran dilakukan sebanyak sembilan kali pertemuan dan di antaranya terdapat dua kali kegiatan praktikum. 
Data yang diperoleh dianalisis dengan menggunakan aplikasi SPSS. Proses uji data hasil penelitian meliputi beberapa tahap yakni, yang pertama uji prasayarat dengan menngunakan uji Kolmogorov Smirnov untuk mengidentifikasi normalitas data yang diperoleh selama melakukan penelitian, dan uji homogenitas yang bertujuan mengetahui sifat homogenitas data hasil penelitian dengan menggunakan uji Levenes Test. Berdasarkan uji prasayarat yang dilakukan, data yang dikumpulkan telah bersifat normal dan homogen sehingga dapat dianalisis lanjut dengan menggunakan analisis Anakova. Hasil Analisis membuktikan bahwa model pembelajaran Remap STAD mempunyai peranan yang sangat signifikan untuk memberdayakan keterampilan literasi sains peserta didik.

HASIL

Tabel 1. Ringkasan Uji Normalitas Data

\begin{tabular}{lcrr}
\hline & & Pretest L.Sains & \multicolumn{1}{c}{ Postest L.Sains } \\
\hline $\mathrm{N}$ & & 102 & 102 \\
Normal Parameters ${ }^{\mathrm{a}, \mathrm{b}}$ & Mean & 56,3824 & 71,2255 \\
& Std. Devision & 7,72170 & 12,41837 \\
& Absolute &, 077 &, 125 \\
MostExtreme Differences & Positive &, 077 &, 063 \\
& Negative &,- 064 &,- 125 \\
Kolmograv Smirnov & &, 776 & 1,267 \\
Asymp Sig (2 tailed) & &, 584 &, 081 \\
\hline
\end{tabular}

Berdasarkan data pada tabel 1, nilai normalitas masing-masing pretest dan posttest adalah 0,584 dan 0,081 yang memiliki angka lebih besar dibandingkan dengan taraf signifikansi 0,05 sehingga dapat disimpulkan bahwa data telah terdistribusi secara normal.

Tabel 2. Ringkasan Hasil Uji Homogentias Data Pretest

\begin{tabular}{cccc}
\hline $\mathbf{F}$ & df1 & df2 & Sig. \\
\hline $\mathbf{1 , 4 5 3}$ & 2 & 99 &, 239 \\
\hline
\end{tabular}

Tabel 3. Ringkasan Hasil Uji Homogentias Data Posttest

\begin{tabular}{cccc}
\hline $\mathbf{F}$ & df1 & df2 & Sig. \\
\hline $\mathbf{1 , 5 3 8}$ & 2 & 99 &, 220 \\
\hline
\end{tabular}

Tabel 2 dan 3 menunjukkan nilai homogenitas data untuk pretest dan posttest secara berurutan 0,239 dan 0,220 dengan nilai yang lebih besar dari taraf signifikansi 5\% sehingga data yang terkumpul selama penelitian telah bersifat homogen. Uji prasayarat menjadi dasar utama terkait akuntabilitas data hasil penelitian dan menggambarkan keadaan data yang telah kita peroleh. Uji prsayarat yang dilakukan telah memenuhi syarat untuk setiap data, sehingga dapat dianalisis lanjut dengan menggunakan uji Anakova. Hasil uji anakova dapat dilihat pada tabel 4.

Tabel 4. Ringkasan Hasil Uji Anakova satu jalur

\begin{tabular}{cccccc}
\hline Source & Type III Sum of Square & df & MS & F & Sig. \\
\hline Corrected Model & $12587,449^{\mathrm{a}}$ & 3 & 4195,816 & 105,395 &, 000 \\
Intercept & 1031,198 & 1 & 1031,198 & 25,903 &, 000 \\
X & 2262,371 & 1 & 2262,371 & 56,829 &, 000 \\
Perlakuan & 3293,990 & 2 & 1646,995 & 41,371 &, 000 \\
Error & 3901,423 & 98 & 39,810 & & \\
Total & 512795,000 & 102 & & & \\
\hline Corrected Total & 16488,873 & 101 & & & \\
\hline
\end{tabular}

Uji anakova membuktikan bahwa nila p $(0,05)$ lebih kecil dibandingkan dengan nilai signifikansi 0,000. Hal ini membuktikan bahwa model pembelajaran Remap STAD berpengaruh dalam memberdayakan keterampilan literasi sains peserta didik.

Tabel 5. Rerata Terkoreksi Variabel Terikat

\begin{tabular}{clcccccc}
\hline No & Kelas & X.Literasi & Y.Literasi & Selisih & LS.Kor & Not & \\
\hline 1 & Remap STAD & 60,088 & 81,235 & 21,147 & 77,385 & a & \\
2 & Kon. + & 55,375 & 71,656 & 16,281 & 71,131 & & b \\
3 & Kon. - & 49,553 & 56,800 & 7,247 & 60,749 & & c \\
\hline
\end{tabular}


Berdasarkan tabel 5, Remap STAD mempunyai nilai rata-rata terkoreksi paling tinggi dibandingkan dengan kelas yan lainnya. Perbandingan kelas yang dibelajarkan dengan menggunakan model pembelajaran Remap STAD mempunyai selisih yang mencapai $16 \%$ sedangkan dengan kelas kontrol positif mencapai $8 \%$. Berdasarkan hasil tersebut dapat disimpulkan bahwa model pembelajaran tersebut mempunyai perbedaan yang paling nyata sehingga hipotesis penelitian diterima.

\section{PEMBAHASAN}

Hasil analisis data penelitian menunjukkan bahwa model pembelajaran Remap STAD mempunyai pengaruh signifikan terhadap keterampilan literasi sains peserta didik. Dukungan sintaks pembelajaran dimulai dengan tahap membaca, yang sangat membantu peserta didik untuk merangkum setiap informasi secara kongkret. Informasi dapat mereka identifikasi dengan jelas melalui sumber bacaan yang diberikan dan dilakukan secara kontiniu (Lawless et al., 2018). Sumber bacaan yang diberikan adalah artikel dan proses pembelajaran juga difasilitasi pemberian UKBK. Peserta didik dapat menggabungkan setiap informasi yang mereka terima sehingga keterampilan literasi mereka meningkat dalam mentransformasi gagasan-gagasan yang unik dan relevan dengan konsep-konsep ilmu pengetahuan yang berlaku secara umum. Penelitian yang dilakukan (Kelly-Laubscher et al., 2017) menunjukkan bahwa dengan menguasai konten materi bacaan peserta didik dapat dengan muda menyatukan setiap persepsi (Kelly-Laubscher et al., 2017).

Tahap berikutnya adalah pembuatan peta konsep. Proses ini mengintegrasikan kemampuan peserta didik untuk dapat menkonstruk lebih komopleks terkait gagasan atau materi yang mereka dapatkan sehingga dapat diaplikasikan dalam suatu peta konsep yang menjabarakan hubungan setiap perspektif yang mereka bentuk secara kronologis (Zubaidah \& Mahanal, 2017). Strategi peta konsep sangat efektif dalam menaytukan ide-ide peserta didik, serta kebenaran informasi ilmiah yang disampaikan peserta didik dapat mereka pertanggungjawabkan dalam kegiatan pembelajaran (Lin, 2011). Penelititan yang dilakukan oleh (Mahanal, Zubaidah, Bahri, \& Dinnurriya, 2016) menunjukkan bahwa peta konsep yang dijabarkan sendiri oleh peserta didik dengan menggunakan bahasa mereka sendiri relatif lebih lama tersimpan di memori dan dapat digunakan secara efisien dalam mengemukakan konsep materi pembelajaran. Berikut contoh peta konsep yang disusun oleh peserta didik.

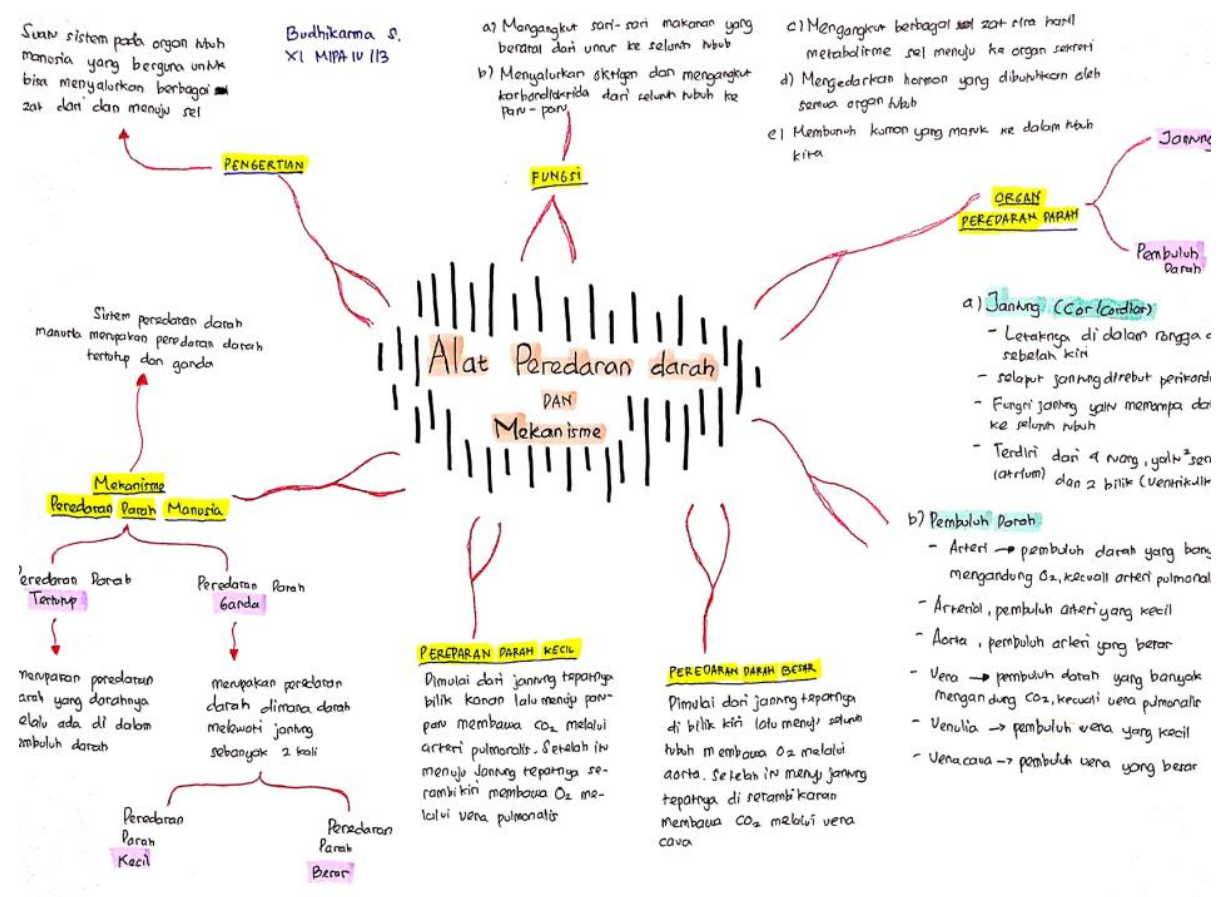

Gambar 1. Peta Konsep Materi Alat Peredaran Darah 


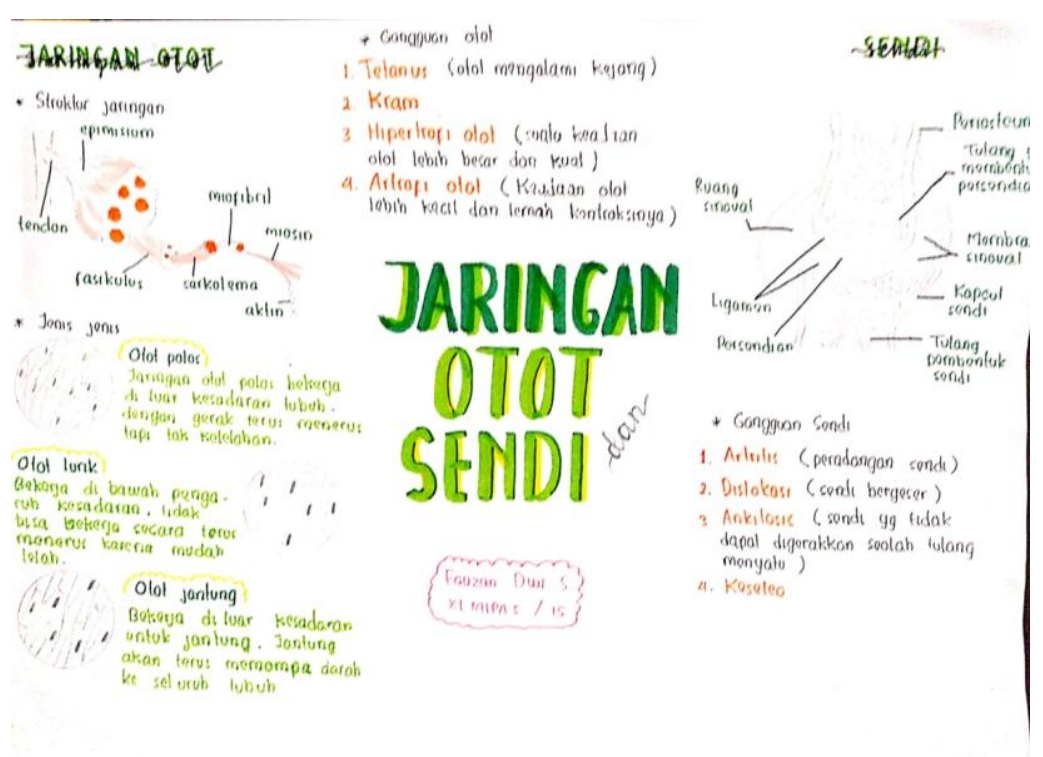

\section{Gambar 2. Peta Konsep Materi Sistem Gerak}

Keunngulan utama peta konsep yang disusun oleh peserta didik adalah mampu menunjukkan pengorganisasian ide-ide secara padu dan menyeluruh serta dapat mengaitkan hubungan antara setiap istilah-istilah penting yang menjadi kunci dalam mengembangkan informasi yang lainnya sehingga mempunyai makna yang jelas (Zubaidah, 2016). Peserta didik mencoba mengonversi gagasan mereka secara berkesinambungan dengan membuat derivasi yang lebih luas terhadap materi yang telah mereka pahami. Akan tetapi, hal ini akan berdampak pada struktur peta konsep yang lebih mengarah ke mind map dan menyerupai rangkuman sederhana. Hal menarik lainnya yang dijumpai adalah adanya penambahan gambar peta konsep yang disusun oleh peserta didik yang membutkikan bahwa mereka menambahkan desain visual yang memudahkan mereka dalam mereview kembali materi yang telah dipelajari.

Pemberdayaan keterampilan literasi sains berorientasi pada kemampuan peserta didik melakukan evaluasi pertanyaan ilmiah yang merupakan aspek dasar keterampilan literasi sains (Miller, 2018). Melalui perspektif yang dihasilkan, mereka dapat secara rinci dan padu menjelaskan kegiatan penyelidikan ilmiah dan mengusulkan cara menjawab pertanyaan ilmiah yang dibuktikan dengan proses evaluasi data sebagai penjabaran akhir yang disusun dalam bentuk kesimpulan ilmiah yang valid (Chowdhury, 2016). Kegiatan pembelajaran yang dilakukan memberikan stimulus kepada peserta didik dalam menciptakan kegiatan diskusi yang efektif dan menarik, serta proses diskusi yang aktif memperluas informasi ilmiah yang diperoleh peserta didik mengarah pada interelasi konsep-konsep sains yang mampu memberdayakan keterampilan literasi sains peserta didik (Turima, 2012).

Literasi sains melatih peserta didik memahami setiap istilah sains dan proses ilmiah yang diperlukan dalam proses pengambilan keputusan, menemukan serta menentukan solusi terhadap permasalahan yang muncul sebagai hasil dari pengalaman belajar peserta didik untuk mendefinisikan, menjelaskan dan memprediksi fenomena sains (Demirel \& Caymaz, 2015). Keaksaraan sains merujuk kepada kapasitas peserta didik untuk dapat mendefinisikan masalah ilmiah, mengevaluasi sumber pengetahuan ilmiah dan metode yang digunakan untuk memperolehnya, sehingga mampu mengevaluasi dan mengemukakan pendapat secara luwes (Miller, 2018). Penyampaian hasil diskusi peserta didik dapat menunjukkan argumen atau bukti yang bersifat ilmiah dari hasil bacaan sebagai dasar dari mereka untuk menemukan gagasan-gagasan baru, yang dapat digunakan untuk mengakses pemaham setiap individu terhadap hasil belajar yang telah mereka terima (Maybee, Carlson, Slebodnik, \& Chapman, 2015).

Proses pembelajaran yang menggunakan model pembelajaran Kooperatif STAD mempunyai peran yang sangat vital untuk mengakomodasi peserta didik memunculkan sikap atau rasa tanggungjawab kepada setiap anggota kelompok mereka (Slavin, 2010). Kegiatan pertama dari model pembelajaran tersebut adalah pengorganisasian kelompok peserta didik dibentuk secara acak dengan tujuan setiap tim dapat bekerja sama dalam mentransfer pengetahuan mereka. Peserta didik mempunyai kesempatan yang sama untuk menyampaikan gagasannya secara terbuka di kelas dan saling menanggapi untuk dapat memperoleh kesimpulan yang umum, sehinnga membantu peserta didik melakukan proses pendefinisian, menjelaskan dan memprediksi fenomena ilmiah dengan berlandaskan pada konsep dasar ilmu sebagai bagian sintesis pengetahuan dari berbagai sumber, mengevaluasi sumber pengetahuan ilmiah dan metode yang digunakan untuk mendapatkannya, mempertimbangkan dampak yang dapat dimunculkan sehingga keterampilan literasi sains peserta didik meningkat secara dinamis (Gormally, Brickman, \& Lut, 2012). 


\section{SIMPULAN}

Berdasarkan hasill penelitian dapat disimpulkan bahwa model pembelajaran Remap STAD mempunyai pengaruh dalam memberdayakan keterampilan literasi sains peserta didik sehingga dapat menjadi solusi alternatif dalam memberdayakan keterampilan literasi sains dan keterampilan abad 21 yang lainnya. Berdasarkan penelitian yang telah dilaksanakan diperoleh hasil bahwa terdapat beberapa peta konsep yang kurang bersesuaian dengan kompetensi dasar yang ingin dicapai dalam kegiatan pembelajaran sehingga peneliti menyarankan agar penelitian selanjutnya menyesuaikan karakter peta konsep dengan kompetensi dasar yang ingin dicapai.

\section{DAFTAR RUJUKAN}

Ahmad, F., Widén, G., \& Huvila, I. (2019). The Impact of Workplace Information Literacy on Organizational Innovation : An Empirical Study. International Journal of Information Management, 51(April), 102041. https://doi.org/10.1016/j.ijinfomgt.2019.102041

Burress, T., Mann, E., \& Neville, T. (2019). Exploring Data Literacy Via a Librarian-Faculty Learning Community: A Case Study. Journal of Academic Librarianship, (September), 102076. https://doi.org/10.1016/j.acalib.2019.102076

Chowdhury, M. (2016). Emphasizing Morals, Values, Ethics, and Character Education in Science Education and Science Teaching. Malaysian Online Journal of Educational Sciences, 4(2), 1-16.

Correia, P. R. M., Xavier do Valle, B., Dazzani, M., \& Infante-Malachias, M. E. (2010). The Importance of Scientific Literacy in Fostering Education for Sustainability: Theoretical Considerations and Preliminary Findings from a Brazilian Experience. Journal of Cleaner Production, 18(7), 678-685. https://doi.org/10.1016/j.jclepro.2009.09.011

Costa, S., \& Caldeira, R. (2018). Bibliometric Analysis of Ocean Literacy: An Underrated Term in the Scientific Literature. Marine Policy, 87(July 2017), 149-157. https://doi.org/10.1016/j.marpol.2017.10.022

Demirel, M., \& Caymaz, B. (2015). Prospective Science and Primary School Teachers' Self-efficacy Beliefs in Scientific Literacy. Procedia - Social and Behavioral Sciences, 191, 1903-1908. https://doi.org/10.1016/j.sbspro.2015.04.500

Diana, S., Rachmatullah, A., \& Rahmawati, E. S. (2015). Profil Kemampuan Literasi Sains Siswa SMA Berdasarkan Instrumen Scientific Literacy Assesments (SLA). Prosiding Seminar Nasional XII Pendidikan Biologi FKIP UNS 2015, $285-291$. Retrieved from https://media.neliti.com/media/publications/171085-ID-none.

Gormally, C., Brickman, P., \& Lut, M. (2012). Developing a Test of Scientific Literacy Skills (TOSLS): Measuring Undergraduates' Evaluation of Scientific Information and Arguments. CBE Life Sciences Education, 11(4), $364-377$. https://doi.org/10.1187/cbe.12-03-0026

Green, C. (2019). A Multilevel Description of Textbook Linguistic Complexity Across Disciplines: Leveraging NLP to Support Disciplinary Literacy. Linguistics and Education, 53, 100748. https://doi.org/10.1016/j.linged.2019.100748

Green, C., \& Lambert, J. (2018). Advancing Disciplinary Literacy Through English for Academic Purposes: Discipline-Specific Wordlists, Collocations and Word Families for Eight Secondary Subjects. Journal of English for Academic Purposes, 35 , 105-115. https://doi.org/10.1016/j.jeap.2018.07.004

Güneş, E., \& Bahçivan, E. (2018). A Mixed Research-Based Model for Pre-Service Science Teachers' Digital Literacy: Responses to "Which Beliefs" and "How and Why They Interact" Questions. Computers and Education, 118, 96-106. https://doi.org/10.1016/j.compedu.2017.11.012

Guo, J., \& Huang, J. (2019). Information Literacy Education in WeChat Environment at Academic Libraries in China. The Journal of Academic Librarianship, (August), 102073. https://doi.org/10.1016/J.ACALIB.2019.102073

Hagermoser Sanetti, L. M., \& Collier-Meek, M. A. (2019). Increasing implementation science literacy to address the researchto-practice gap in school psychology. Journal of School Psychology, 76, 33-47. https://doi.org/10.1016/j.jsp.2019.07.008

Kaya, V. H., Bahceci, D., \& Altuk, Y. G. (2012). The Relationship Between Primary School Students' Scientific Literacy Levels and Scientific Process Skills. Procedia - Social and Behavioral Sciences, 47, 495-500. https://doi.org/10.1016/j.sbspro.2012.06.687

Kelly-Laubscher, R. F., Muna, N., \& van der Merwe, M. (2017). Using the Research Article as a Model for Teaching Laboratory Report Writing Provides Opportunities for Development of Genre Awareness and Adoption of New Literacy Practices. English for Specific Purposes, 48, 1-16. https://doi.org/10.1016/j.esp.2017.05.002

Lawless, K. A., Brown, S. W., Rhoads, C., Lynn, L., Newton, S. D., Brodowiksa, K. Wang, M. (2018). Promoting Students' Science Literacy Skills Through a Simulation of International Negotiations: The GlobalEd 2 Project. Computers in Human Behavior, 78, 389-396. https://doi.org/10.1016/j.chb.2017.08.027

Lin, Y. S. (2011). Fostering Creativity through Education - A Conceptual Framework of Creative Pedagogy. Creative Education, 02(03), 149-155. https://doi.org/10.4236/ce.2011.23021

Mahanal, S., Zubaidah, S., Bahri, A., \& Dinnurriya, M. S. (2016). Improving Students' Critical Thinking Skills Through Remap NHT in Biology Classroom. Asia-Pacific Forum on Science Learning and Teaching, 17(2).

Maybee, C., Carlson, J., Slebodnik, M., \& Chapman, B. (2015). "It's in the Syllabus": Identifying Information Literacy and Data Information Literacy Opportunities Using a Grounded Theory Approach. Journal of Academic Librarianship, 41(4), 369-376. https://doi.org/10.1016/j.acalib.2015.05.009 
Miller, S. D. (2018). Diving Deep: Reflective Questions for Identifying Tacit Disciplinary Information Literacy Knowledge Practices, Dispositions, and Values through the ACRL Framework for Information Literacy. Journal of Academic Librarianship, 44(3), 412-418. https://doi.org/10.1016/j.acalib.2018.02.014

Nwagbo, C. (2006). Effects of Two Teaching Methods on The Achievement and Attitude to Biology of Students of Different Levels of Scientific Literacy. International Journal of Educational Research, 45(3), 216-229. https://doi.org/10.1016/j.ijer.2006.11.004

Reiska, P., Soika, K., Möllits, A., Rannikmäe, M., \& Soobard, R. (2015). Using Concept Mapping Method for Assessing Students' Scientific Literacy. Procedia - Social and Behavioral Sciences, 177(July 2014), 352-357. https://doi.org/10.1016/j.sbspro.2015.02.357

Sample, A. (2020). The Journal of Academic Librarianship Historical Development of Definitions of Information Literacy : A Literature Review of Selected Resources. (December 2019). https://doi.org/10.1016/j.acalib.2020.102116

Slavin, R. E. (2010). Cooperative Learning. International Encyclopedia of Education, (Cl), 177-183. https://doi.org/10.1016/B978-0-08-044894-7.00494-2

Turiman, P., Omar, J., Daud, A. M., \& Osman, K. (2012). Fostering the 21st Century Skills through Scientific Literacy and Science Process Skills. Procedia - Social and Behavioral Sciences, 59, 110-116. https://doi.org/10.1016/j.sbspro.2012.09.253

Zubaidah, S. (2016). Keterampilan Abad Ke-21 : Keterampilan yang Diajarkan melalui Pembelajaran. Seminar Nasional Pendidikan, 21(2), 1-17.

Zubaidah, S., \& Corebima, A. D. (2016). Remap Coople (1st ed.). Malang: Aditya Media Publishing.

Zubaidah, S., \& Mahanal, S. (2017). Model Pembelajaran Ricosre yang Berpotensi Memberdayakan Keterampilan Berpikir Kreatif. Jurnal Pendidikan: Teori, Penelitian, dan Pengembangan, 2(5), 676-685. 